\title{
Project management business game
}

\author{
Renato de Oliveira Moraes, André Heleno Batista \\ University of São Paulo \\ e-mails: remo@usp.br; andrecefetri@gmail.com
}

\begin{abstract}
This paper presents a project management game that evolves based on the participant's skills on time, cost and quality management. The game comes to the construction of a refinery unit whose activities are divided into three phases in which the player acts as the project manager, decides the resources allocation, and ensures that the project meets its cost, time and quality targets. The game was played using a spreadsheet to simulate the project in seven rounds. The dynamic was developed basically in the classroom with engineering undergraduate students divided into ten groups. In each round, the scene was updated by a newspaper that reported the results in graphs and offered some tips. The goal was achieved with the participants making more mature decisions and improving their perception of cost estimates, time and quality.
\end{abstract}

Keywords: business game, business simulation, project management.

\section{Introduction}

According to Glynn, Aultman and Owens (2005), the use of interactive educational resources such as games and simulations are important educational tools that can be used combined with conventional methods such lectures (LAW; KELTON, 1991; KIILI, 2005; TAN, 2007; TAN; TSE; CHUNG, 2010; LIN; TU, 2012) in order to improve the student learning (ALIYA, 2002; VIRVOU; KATSIONIS; MANOS, 2005).

Computer simulation has been used in a lot of disciplines (JACKSON, 2004), and the business games or business simulation appear to be particularly effective tools in teaching management techniques (BIRKNEROVÁ, 2010; GILGEOUS; D'CRUZ, 1996; MAWDESLEY et al., 2011; TAL, 2010; WALL; AHMED, 2008; YASARCAN, 2010).

Gramigna (1993) says that the simulations are characterized by a situation in which a simulated scenario acts as a real model. Thus, when employees are put in simulations of certain activities, they can acquire skills faster and closer to the real world, without taking on large projects and business risks. The Business Games are an exercise with a number of decision-making moments, structured around a model of a business situation, in which participants take charge of the task of managing the simulated companies. The goal is the training of the participants, teaching of techniques and scenarios for observing certain skills. The participants are stimulated to adopt the target behavior and evaluate the results through the game stages.

The Polytechnic School of the University of São Paulo prepares its engineering students with a range of multidisciplinary skills that are critical in the formation of higher professional qualification. Among these skills is the project management which is treated in undergraduate courses and graduate.

This article presents a business game developed for an undergraduate course to students of final year of Electrical Engineering. This game was developed with the intention to simulate the impact of decisions on some of the project management areas described in the PMBOK (Projetct Mangement Body of Knowledge).

The game was developed as an extension project of the Edital Aprender com Extensão of University of São Paulo, and its duration was one year.

Next section shows the methodology used in the design and development of the game. The third part describes in detail the game developed and the interested reader could recreate this game. In the fourth part we discuss the results and possible improvements.

\section{Methodology}

In order to achieve the objectives of this project, a sequential division of project development steps in the following order was performed:

1. Bibliographic review about business games, project management education and business game in project management;

2. Choice of the core competencies and skills to be included in the game;

3. Design of the model; 
4. Build a prototype and tests;

5. Game implementation in the classroom;

6. Feedback from participants.

The development of steps 1-4 of the game were performed before the beginning of classes of Project Management Principles course. In step 5, the students were divided into groups and they started to play and make weekly decisions. The game developers realized that would be important to create a fictional participant, controlled by them, which also participated in the match, which always took the best possible decisions and served as an important indicator of the proper functioning of the game. After that last round of the game (round 6), the players had to write their opinions about their performances and about the game.

\section{Results and analysis}

The game architecture was very close of that described by Martin (2000). The group was responsible for allocate the best supplier for each activity of the project. This choice had an impact in the three dimensions of the performance of the activities and of the project: cost, time and quality. The simulation of the decisions used a MS Excel ${ }^{\mathrm{TM}}$ spreadsheet. Thereby there was not a direct competition among groups; a decision of one team did not have any impact in other groups.

\subsection{Management skills}

The PMBoK shows ten knowledge areas about project management but in this game just three of them are considered: cost, time and quality. It was expected that the students develop certain skills as working under uncertainty, incomplete information, time pressure, and realize the temporal relationship between decisions and their consequences. So the competences that the students should present are:

- Work with defined activities;

- Allocate the resources for each activity;

- Estimate activity durations;

- Estimate and control costs;

- Develop a schedule;

- Determine the budget;

- Analyze the performance;

- Control Schedule;

- Perform quality assurance to hire well-qualified suppliers; and

- Control the quality to make high quality meter index.

\subsection{The model}

The next step was to set a scenario in which happened to be the construction of a refinery. Although there are other good scenarios, as a development of a product, we chose to work with the construction of the refinery because of a scenario in which it is very necessary acting together engineers from different areas and an excellent project manager is always necessary to flow the work of each team and the whole building.

However, building a refinery is not an easy task to summarize and apply a single match. Normally refineries have multiple drives, such as the Atmospheric Distillation Unit, a Hydrogen Generation Unit and, among others, the Unit Delayed Coking, as well as other sectors such as tankage, the Pipe Racks, the Power House and substations which are connected to the units. Since there is similarity in construction of refinery units, the chosen scenario was the Hydrogen Generation Unit that is the most common in refineries and less complicated to construct, so it was possible to build the dynamics of the game with tasks and data closer to reality.

A research was done in some research on Hydrogen Generation Units of important refineries being built in Brazil, such as RNEST, the Petrobras refinery being built in the Northeast. Thus, a better understanding of the features of this unit and its construction process was possible through information about the engineering disciplines required for drawing up the construction project, the main activities and duration of each.

The main engineering disciplines required for the construction projects of the Hydrogen Generation Unit are Process, Piping, Civil, Mechanical, Instrumentation and Automation, Security and Electric. All these disciplines were considered in the game scenario.

Table 1 shows the activities in the construction of this unit. The simulation was divided into three phases, which are a sequence of activities with a clear beginning and ending. Each phase finishes with an overall integration activity of all the activities developed at that stage.

Each of these phases had particular characteristics. Phase I is about the preparation of projects and basic documents of the disciplines that are responsible for starting the whole project (Process, Civil and Piping). Phase II details the stage of the documents of the teams that have already started their activities in the previous phase, but it is also the time when the disciplines Electrical, Instrumentation and Automation and Security start their work with their basic designs. Finally, phase III concludes all activities with details of the subjects who performed their basic projects in Phase II and with the completion of important document Operating Manual Hydrogen Generation Unit that was being prepared from phase I by team processes. 
Table 1. Project Activities.

\begin{tabular}{|c|c|c|c|c|}
\hline $\mathrm{N}^{\mathrm{o}}$ & ACTIVITY & PRE & Duration (days) & \$/day \\
\hline \multicolumn{5}{|c|}{ Stage I } \\
\hline 1 & General requirements and specifications & - & 45 & $\mathrm{R} \$ 11,275.00$ \\
\hline 2 & Process basic design & 1 & 30 & $\mathrm{R} \$ 1,950.00$ \\
\hline 3 & Flowcharts and process engineering & 2 & 25 & $\mathrm{R} \$ 4,000.00$ \\
\hline 4 & Pipe Lines Drafts & 2 & 20 & $\mathrm{R} \$ 3,950.00$ \\
\hline 5 & Mechanics basic project & 2 & 20 & $\mathrm{R} \$ 1,825.00$ \\
\hline 6 & Pipe basic project & 3 & 20 & $\mathrm{R} \$ 2,050.00$ \\
\hline 7 & Basic project of civil construction works & 4 & 20 & $\mathrm{R} \$ 2,000.00$ \\
\hline 8 & Operation manual part $1 / 3$ & 5 & 15 & $\mathrm{R} \$ 1,950.00$ \\
\hline 9 & Integration of stage I projects & $6 ; 7 ; 8$ & 15 & $\mathrm{R} \$ 11,275.00$ \\
\hline \multicolumn{5}{|c|}{ Stage II } \\
\hline 10 & Plants P \& I (Process and Instrumentation) & 9 & 15 & $\mathrm{R} \$ 1,950.00$ \\
\hline 11 & Process detailed project & 10 & 70 & $\mathrm{R} \$ 1,950.00$ \\
\hline 12 & Electric basic project & $11 ; 14$ & 30 & $\mathrm{R} \$ 1,825.00$ \\
\hline 13 & Pipe detailed project & 10 & 35 & $\mathrm{R} \$ 2,050.00$ \\
\hline 14 & Mechanics detailed project & 13 & 30 & $\mathrm{R} \$ 1,825.00$ \\
\hline 15 & Detailed project of civil construction works & $11 ; 14$ & 60 & $\mathrm{R} \$ 2,000.00$ \\
\hline 16 & Instrumentation and automation basic project & 12 & 24 & $\mathrm{R} \$ 1,775.00$ \\
\hline 17 & Electrical substations & $12 ; 18$ & 30 & $\mathrm{R} \$ 1,825.00$ \\
\hline 18 & Safety basic design & 11 & 10 & $\mathrm{R} \$ 950.00$ \\
\hline 19 & Operation manual part $2 / 3$ & 14 & 25 & $\mathrm{R} \$ 1,950.00$ \\
\hline 20 & Integration of stage II projects & $15 ; 16 ; 17 ; 19$ & 15 & $\mathrm{R} \$ 11,275.00$ \\
\hline \multicolumn{5}{|c|}{ Stage III } \\
\hline 21 & Electric detailed project & 20 & 75 & $\mathrm{R} \$ 1,825.00$ \\
\hline 22 & Instrumentation and automation detailed project & 21 & 75 & $\mathrm{R} \$ 1,775.00$ \\
\hline 23 & Safety detailed design & 21 & 40 & $\mathrm{R} \$ 950.00$ \\
\hline 24 & Operation manual part $3 / 3$ & 23 & 50 & $\mathrm{R} \$ 2,050.00$ \\
\hline 25 & Integration of stage III projects & $22 ; 24$ & 25 & $\mathrm{R} \$ 11,275.00$ \\
\hline
\end{tabular}

The intention was to create a game in which the player would act as the project manager responsible for the construction of the refinery unit. The scenario was limited to working with only the activities related to preparation of engineering projects, only with the issuance of documents, such as plants, memories calculations and diagrams, with no involvement with the work itself. The player would have to hire service companies, which had the necessary engineering teams to perform the tasks, and stay tuned to the costs, quality and deadlines for completion.

\subsection{Construction of the prototype}

The prototype was based on data from Table 1. Additionally was defined the type of resource - specialized engineering discipline - necessary for each activity, and a project completion deadline.

For the execution of activities, eleven service providers were created. These suppliers had some or all of the teams of engineering disciplines. Each team of each company had three levels of efficiency:

- Duration Efficiency Index (DEI), indicates how quickly or slowly was a team;
- Cost Efficiency Index (CEI), a percentage of the cost of each activity, how much each company team services provider would charge for the execution of their work;

- Quality Index (QI), shows how good are the service of the team.

Table 2 shows the 11 suppliers and their indices (in percentage) about the team of Civil Engineering. It is possible so see that some companies do not offer this discipline, this means that they do not have the staff of this discipline. Appendix A shows the details of each company in relation to other disciplines (Table A1) and an example of the evolution of project performance for one group (Table A2 and Figure A1).

From those indexes the player selects the best company to perform a certain activity. However, this choice it is not an easy task, usually a team was strong in an index and average or weak in another. The result of each activity is presented in fields like Actual Cost, Actual Time and Quality.

Regarding the final quality of an activity, two factors should be considered: the Quality Index (QI) of the supplier's staff chosen and the quality of previous activity (QP). Furthermore it was necessary to establish a link 
Table 2. Qualifications of suppliers of Civil Engineering.

\begin{tabular}{|l|c|c|c|}
\hline \multirow{2}{*}{ Supplier } & \multicolumn{3}{|c|}{ CIVIL } \\
\cline { 2 - 4 } & DEI & CEI & QI \\
\hline Alfa & $270 \%$ & $80 \%$ & $65 \%$ \\
\hline Gama & $260 \%$ & $60 \%$ & $80 \%$ \\
\hline Iota & $150 \%$ & $130 \%$ & $60 \%$ \\
\hline Lambida & & & \\
\hline Delta & $160 \%$ & $55 \%$ & $130 \%$ \\
\hline Epsilon & & & \\
\hline Mem & & & \\
\hline Teta & & & \\
\hline Beta & $250 \%$ & $35 \%$ & $150 \%$ \\
\hline Sigma & $140 \%$ & $75 \%$ & $75 \%$ \\
\hline Kappa & & & \\
\hline
\end{tabular}

between them to obtain the final quality, thus the Equation 1 shows this relationship.

$$
\text { Final Quality of the Activity }(F Q)=\frac{3 \times I Q+Q P}{4}
$$

Some activities have more than one previous activity. In such cases, the QP value in this case was obtained by harmonic average of the quality indexes of the foregoing activities.

The quality of a work is strongly associated to the time of completion. This becomes clear when rework are required to correct previous services, resulting in longer, beyond the expected, dedicated to performing a task. Thus, Equation 2 shows the actual time spent for a team to perform an activity.

$$
\text { Actual Duration of the Activity }(F Q)=\frac{\text { Original Duration }}{D E I \times F Q^{2}}
$$

These values are strongly connected with the cost of each activity. Of course, require more days of delay costs for labor and lousy jobs require rework, which means more expenses. Thus, the Equation 3 shows the expression used in the calculation of the actual cost of an activity.

Actual Cost of the Activity $(A C)=\frac{(\text { Original } \$ / \text { Day }) \times D u r}{C E I}$

The simulation was performed using the MS Excel spreadsheet with appropriate formulas for the construction of the rules of the game, and the relationships between decisions taken by the player and their consequences.

Through the Excel software, the whole game was developed in a single document, which had mainly three important spreadsheets:

- Suppliers Worksheet with all the characteristics of service providers;
- Spreadsheet of Decisions which served to record the choices of the players with their consequences; and

- Simulation sheet with a structure to carry out the decisions necessary for the activities and presentation of results.

With these worksheets, some tests were carried out and the necessary adaptations was done before the game be applied in the classroom.

\subsection{Use in the classroom}

The implementation of the game was made by professor of anthropology during their classes. The duration of each decision round was approximately 20 minutes. Initially, a classroom with students of the last year of the Electrical Engineering course was divided into 10 groups of maximum 5 students. Each group was responsible for the management of a project, and during the weeks the performance of each group was compared with others.

One of the rules was that the group that delayed the delivery of their decisions were punished. Even in the classroom, the delay time counted in minutes to deliver the decision of each round to the teacher was recorded and become "days late" for the project. Thus, the teams had to make its decisions within the time limit that was determined.

The game was divided into 7 rounds, numbered $0-6$, so that every week the group held a round of decisions and receive information about the consequences of their decisions in the previous round. Figure 1 illustrates the division of labor in each round and their precedence note that the activities are indicated by corresponding numbers (see Table 1).

The decisions of participants in previous rounds, as well as predictions about the future of the projects and suggestions to improve the groups were disclosed by means of a journal called "O Hebdomadário". Each round a new edition with news, suggestions, tables and updated graphics that compared the performance of groups was prepared and distributed.

In round 0 the groups had to decide how long would prospecting companies providing engineering services in the market. How much longer the prospecting, the greater the tendency of identified which all companies available in the market, however the beginning of the execution of project activities started later and later. This amount of time dedicated to the choice of supplier was considered in the project schedule for each group.

In each game round the players were given a sheet with a report on the status of the activities already carried out, information on the activities to be performed and contract decisions need to be made. It was also distributed the latest edition of the weekly newspaper. After each class decisions 


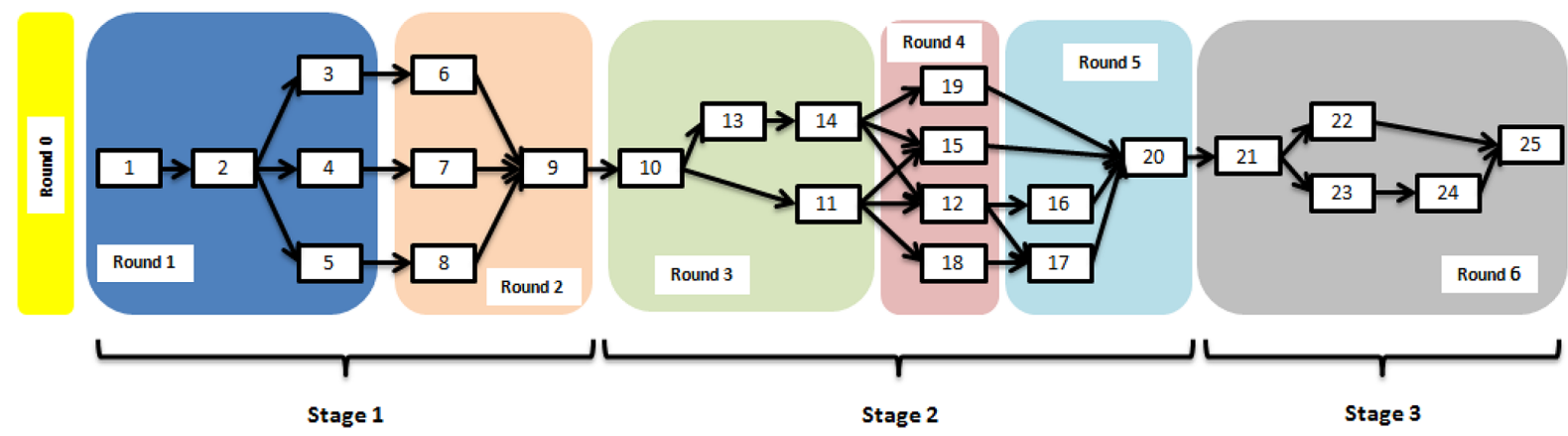

Figure 1. Game rounds.

were recorded in MS Excel spreadsheets, the decisions were simulated and the results shown in tables and graphs.

The game code, which can be summed up in the formulas of the consequences of decisions, always remained inaccessible to students. Similarly, during the first three rounds each index of service providers was reported in aggregate form only (good, fair or poor) which brought some more difficulties to the players. However, from the third round, with these figures were available in the newspaper and the groups were forced to draw up a control sheet that estimated the consequences of their decisions.

With the advancement of rounds, participants received a maturity in their decisions. It became clear to them the importance of careful estimates of costs, time and quality, and understand how the choice of suppliers is important for the success of projects.

Some groups have made it clear that delays in the delivery of decisions in the classroom were the ones that most affected the schedule. On the other hand, the availability of more detailed information from providers and the implementation of the control sheet, as a project management tool, have had a positive impact on the results of most groups.

In the end, superior performance of one group noted, called G4, which due to their good decisions, managed to complete the project ahead of schedule, with the lowest cost compared to other players and acceptable quality. See Appendix B to the graphic and table showing their performance. For this group the most important aspect was to wait any longer to make a good selection of suppliers in round 0 , pay attention to the newspaper's information, which indicated the main factors that most participants needed improvement, and run a successful teamwork the division of labor. Thus, the relative backwardness acquired in the round 0 was offset by the good work the other stages in the game.

\section{Final remarks}

The game application went smoothly, the existing physical conditions in the institution were adequate, and it was clear that other scenarios could be used. It was revealed that a version of the game within the software (to be developed) will allow players to place their answers directly in the program and receive faster results of each round.

After the implementation in the classroom and analysis of the final results of the teams, it can be concluded that this game earned his success. Although most groups get higher costs than planned at the end of the game, some managed to stand out in avoiding over costs, while others have had good performances in attention to quality and deadlines.

In fact, during the dynamic of each round, it was clear the interaction among group members and the search for improvement of their performance by following the newspaper's suggestions, looking for ways to improve their projects performance and achieve the best results.

Thus, this business game was an important activity for the development of students as engineers. The determination of the model and the goal crated the road for the next steps, and the implementation in the classroom was important for the interaction of the players and for the simulation of the consequences of some project management areas described in the PMBOK.

\section{References}

ALIYA, S. K. The role of computer games in the development of theoretical analysis, flexibility and reflective thinking in children: a longitudinal study. International Journal of Psychophysiology, v. 45, n. 1-2, p. 149-159, 2002.

BIRKNEROVÁ, Z. The use of simulation business games in university education. Bulgarian Journal of Science and Education Policy, v. 4, n. 2, p. 202-215, 2010.

GILGEOUS, V.; D'CRUZ, M. A study of business and management games. Management Development Review, v. 9, n. 1, p. 32-40, 1996. http://dx.doi. org/10.1108/09622519610181757.

GLYNN, S. M.; AULTMAN, L. P.; OWENS, A. M. Motivation to learn in general education programs. The Journal of General Education, v. 54, n. 2, p. 150-170, 2005. http:// dx.doi.org/10.1353/jge.2005.0021. 
GRAMIGNA, M. R. M. Jogos de empresa. São Paulo: Makron Books, 1993. $138 \mathrm{p}$.

JACKSON, M. Making visible: using simulation and game environments across disciplines. On the Horizon, v. 12, n. 1, p. 22-25, 2004. http://dx.doi. org/10.1108/10748120410540463.

KIILI, K. Digital game-based learning: towards an experiential gaming model. The Internet and Higher Education, v. 8, n. 1, p. 13-24, 2005. http://dx.doi.org/10.1016/j. iheduc.2004.12.001.

LAW, A. M.; KELTON, W. D. Simulation modeling and analysis. New York: McGraw-Hill, 1991.

LIN, Y. L.; TU, Y. Z. The values of college students in business simulation game: a means-end chain approach. Computers \& Education, v. 58, n. 4, p. 1160-1170, 2012. http://dx.doi. org/10.1016/j.compedu.2011.12.005.

MARTIN, A. A simularion engine for custom Project management education. International Journal of Project Management, v. 18, n. 3, p. 201-213, 2000. http://dx.doi. org/10.1016/S0263-7863(99)00014-9.

MAWDESLEY, M. et al. The enhancement of simulation based learning exercises through formalized reflection, focus groups and group presentation. Computers \& Education, v. 56, n. 1, p. 44-52, 2011. http://dx.doi.org/10.1016/j. compedu.2010.05.005.
TAL, B. Z. The efficacy of business simulation games in creating decision support systems: an experimental investigation. Decision Support Systems, v. 49, n. 1, p. 61-69, 2010. http://dx.doi.org/10.1016/j.dss.2010.01.002.

TAN, K. H. Comparing games and case methods in enhancing student learning. International Journal of Innovation and Learning, v. 4, n. 3, p. 224-236, 2007. http://dx.doi. org/10.1504/IJIL.2007.012379.

TAN, K. H.; TSE, Y. K.; CHUNG, P. L. A plug and play pathway approach for operations management games development. Computers \& Education, v. 55, n. 1, p. 109-117, 2010. http://dx.doi.org/10.1016/j.compedu.2009.12.008.

VIRVOU, M.; KATSIONIS, G.; MANOS, K. Combining software games with education: evaluation of its educational effectiveness. Journal of Educational Technology \& Society, v. 8, n. 2, p. 54-65, 2005.

WALL, J.; AHMED, V. Use of a simulation game in delivering blended lifelong learning in the construction industryopportunities and challenges. Computers \& Education, v. 50, n. 4, p. 1383-1393, 2008. http://dx.doi.org/10.1016/j. compedu.2006.12.012.

WAUTELET, Y.; KOLP, M. An online software project management game. International Journal of Engineering Education, v. 28, n. 6, p. 1316-1325, 2012.

YASARCAN, H. Improving understanding, learning, and performances of novices in dynamic managerial simulation games. Complexity, v. 15, p. 31-42, 2010. 
Appendix A. Characteristics of the suppliers.

Table A1. Qualifications of suppliers.

\begin{tabular}{|c|c|c|c|c|c|c|c|c|c|c|c|c|}
\hline \multirow{2}{*}{ SUPPLIERS } & \multicolumn{3}{|c|}{ PROCESSES } & \multicolumn{3}{|c|}{ ELETRIC } & \multicolumn{3}{|c|}{ MECHANICAL } & \multicolumn{3}{|c|}{ PIPE } \\
\hline & DEI & CEI & QI & DEI & CEI & QI & DEI & CEI & QI & DEI & CEI & QI \\
\hline Alfa & $80 \%$ & $140 \%$ & $80 \%$ & $150 \%$ & $150 \%$ & $60 \%$ & $80 \%$ & $70 \%$ & $180 \%$ & $80 \%$ & $140 \%$ & $80 \%$ \\
\hline Gama & $80 \%$ & $80 \%$ & $170 \%$ & $60 \%$ & $150 \%$ & $90 \%$ & $150 \%$ & $150 \%$ & $50 \%$ & $80 \%$ & $80 \%$ & $170 \%$ \\
\hline Iota & $70 \%$ & $140 \%$ & $100 \%$ & $140 \%$ & $70 \%$ & $100 \%$ & & & & $70 \%$ & $140 \%$ & $100 \%$ \\
\hline Lambida & & & & $80 \%$ & $70 \%$ & $180 \%$ & & & & & & \\
\hline Delta & $150 \%$ & $150 \%$ & $50 \%$ & & & & & & & $150 \%$ & $150 \%$ & $50 \%$ \\
\hline Epsilon & & & & $70 \%$ & $90 \%$ & $170 \%$ & & & & & & \\
\hline Mem & & & & & & & $140 \%$ & $90 \%$ & $80 \%$ & & & \\
\hline Teta & & & & & & & & & & & & \\
\hline Beta & $140 \%$ & $70 \%$ & $90 \%$ & $80 \%$ & $60 \%$ & $180 \%$ & $70 \%$ & $80 \%$ & $90 \%$ & $140 \%$ & $70 \%$ & $90 \%$ \\
\hline Sigma & $140 \%$ & $90 \%$ & $70 \%$ & & & & $90 \%$ & $80 \%$ & $150 \%$ & $140 \%$ & $90 \%$ & $70 \%$ \\
\hline Kappa & & & & & & & $60 \%$ & $160 \%$ & $80 \%$ & & & \\
\hline
\end{tabular}

\begin{tabular}{|c|c|c|c|c|c|c|c|c|c|}
\hline \multirow{2}{*}{ SUPPLIERS } & \multicolumn{3}{|c|}{ INST. \& AUTOMATION } & \multicolumn{3}{|c|}{ SAFETY } & \multicolumn{3}{|c|}{ MULTIDISCIPLINAR } \\
\hline & DEI & CEI & QI & DEI & CEI & QI & DEI & CEI & QI \\
\hline Alfa & $170 \%$ & $150 \%$ & $70 \%$ & $90 \%$ & $80 \%$ & $70 \%$ & $140 \%$ & $90 \%$ & $80 \%$ \\
\hline Gama & $150 \%$ & $90 \%$ & $70 \%$ & $70 \%$ & $80 \%$ & $180 \%$ & $80 \%$ & $140 \%$ & $90 \%$ \\
\hline Iota & $70 \%$ & $80 \%$ & $170 \%$ & & & & & & \\
\hline Lambida & & & & $80 \%$ & $70 \%$ & $180 \%$ & & & \\
\hline \multicolumn{10}{|l|}{ Delta } \\
\hline Epsilon & & & & $90 \%$ & $140 \%$ & $160 \%$ & & & \\
\hline \multicolumn{10}{|l|}{ Mem } \\
\hline Teta & $80 \%$ & $70 \%$ & $150 \%$ & $140 \%$ & $90 \%$ & $80 \%$ & & & \\
\hline Beta & $90 \%$ & $60 \%$ & $90 \%$ & $150 \%$ & $70 \%$ & $90 \%$ & $140 \%$ & $70 \%$ & $140 \%$ \\
\hline \multicolumn{10}{|l|}{ Sigma } \\
\hline Kappa & $80 \%$ & $80 \%$ & $100 \%$ & & & & & & \\
\hline
\end{tabular}

Comments:

1) Indexes for Civil discipline are presented in Table 2;

2) "Multidisciplinary" means that the company has all disciplines.

Appendix B. Group B results at the end of the simulation.

Table A2. Project Perfomance Evolution.

\begin{tabular}{|c|c|c|c|c|c|}
\hline Round & $\Delta \mathrm{T}$ Period & $\Delta \mathrm{T}$ Accumulated & $\Delta \mathrm{T}$ Period & $\Delta \mathrm{T}$ Accumulated & QI \\
\hline 0 & 0 & 0 & 0 & 0 & 1 \\
\hline 1 & $52 \%$ & $91 \%$ & $67 \%$ & $67 \%$ & 1.04 \\
\hline 2 & $100 \%$ & $86 \%$ & $99 \%$ & $75 \%$ & 0.67 \\
\hline 3 & $-44 \%$ & $38 \%$ & $-34 \%$ & $52 \%$ & 1.37 \\
\hline 4 & $-60 \%$ & $15 \%$ & $-39 \%$ & $38 \%$ & 1.42 \\
\hline 5 & $20 \%$ & $23 \%$ & $-17 \%$ & $30 \%$ & 0.66 \\
\hline 6 & $-46 \%$ & $-4 \%$ & $-29 \%$ & $14 \%$ & 0.79 \\
\hline
\end{tabular}

Obs:

1) " $\Delta \mathrm{T}$ Period" is the relation of the actual time spent over the time planned for the round;

2) " $\Delta \mathrm{T}$ Accumulated" is the relation of the total time spent calculated from the beginning of the project until the round completion over the total planned time;

3) " $\Delta \$$ Period" is the relation of the round actual expense over the round planned cost;

4) " $\Delta \$$ Accumulated" is the relation of the actual total spending calculated from the beginning of the project until the round completion over total planned cost;

5) "QI" means the final quality. 


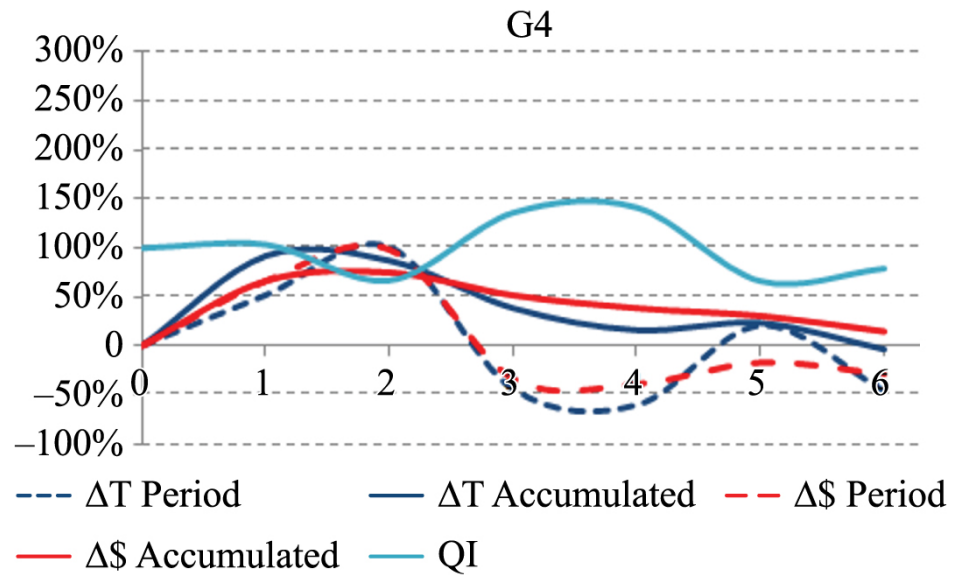

Figure A1. Perfomance Evolution. 